\title{
A Case-Based Look at Healthy Weight Loss for Survivors of Cancer
}

\author{
KRISTY K. HAGER, MS, RD, CSO, LDN
}

From Wellmont Cancer Institute, Kingsport, Tennessee

Author's disclosures of potential conflicts of interest are found at the end of this article.

Correspondence to: Kristy K. Hager, MS, RD, CSO, LDN, Wellmont Cancer Institute, 4485 West Stone Drive, Suite 200, Kingsport, TN 37660

E-mail: kristy.hager@wellmont.org

doi: 10.6004/jadpro.2016.7.2.8

(1) 2016 Harborside Press ${ }^{\circledR}$

\section{CASE STUDY}

Ms. $D$ is a 47-year-old female who was diagnosed with stage IIIA triple-negative breast cancer in 2014. She completed neoadjuvant therapy with doxorubicin, cyclophosphamide, and paclitaxel and then had a left mastectomy and radiation therapy.

During an appointment in the survivorship clinic, she reveals to her advanced practitioner (AP) and dietitian that she is concerned about her weight. Her body mass index (BMI) is $42.5 \mathrm{~kg} / \mathrm{m}^{2}$, which places her in the obese category. She has multiple questions regarding weight loss, including the use of phentermine, and is interested in losing weight "the fastest way possible." She is only eating one meal a day in an attempt to lose weight. Other than obesity, her physical examination is normal, and her laboratory results are unremarkable.

The AP discussed Ms. D's BMI with her. She reviewed the risk of cancer recurrence, noting that a BMI of $\geq 35 \mathrm{~kg} / \mathrm{m}^{2}$ may be associated with a higher risk of recurrence. She emphasized the role of exercise in weight loss. She encouraged Ms. D to begin an exercise routine at 5 minutes per day and work up to a goal of 30 minutes of moderate to strenuous exercise at least 5 days per week. Ms. D stated that there is a track near her home and that she could begin walking daily there.

The AP stressed the importance of following good nutritional guidelines and eating from every food group. She reviewed the safety data on phentermine, specifically the cardioexcitatory effects. She noted that long-term efficacy and safety evidence is lacking.

The dietitian discussed Ms. D's desire for rapid weight loss. She educated her on healthy weight loss, which may seem slow but is much better for the body. She encouraged colorful, healthy food from all food groups such as fruits and vegetables, whole grains, beans, lean meats, and avoiding processed items such as fast foods and convenience foods. The dietitian discussed the importance of hydration, and Ms. D revealed that she drinks about three cola drinks and at least one glass of sweetened iced tea per day. The dietitian told her that caffeine-free and calorie-free beverages are best for hydration, stressing that water is the healthiest choice.

The dietitian asked about Ms. D's meal setting. She said that she eats in front of the TV daily. It was recommended that she eliminate 
distractions and eat with the TV off, so she would be more cognizant of portion size and stop eating when she was satisfied. She encouraged Ms. D to take smaller bites and chew slowly to help minimize overeating by giving the satiety center in the brain time to receive messages of fullness from the stomach.

The dietitian discussed the need for weight loss utilizing adequate nutritional intake vs. a "quick-fix" pill such as phentermine. A calorie-restricted diet is still required for weight loss when using phentermine. Weight is usually rapidly regained after the drug is stopped unless there are behavioral and lifestyle changes. She gave Ms. D a tip sheet for successful weight loss, including having consistent meal times, avoiding skipping meals, using portion control, limiting alcohol intake, eating meals in one specified location, and adequate hydrating with noncaloric, caffeine-free liquids. They brainstormed about healthy snacks to have on hand, and Ms. D said she likes apples, raisins, and yogurt. The dietitian gave her some ideas about planning ahead for lunches to take to work, so she could avoid fast food. They discussed other times of temptation to overeat and ways to prevent it, all with a goal of long-term, sustainable weight reduction.

J Adv Pract Oncol 2016;7:227-232

verweight and obesity are terms used for ranges of weight that are greater than what is generally considered healthy for a given height (Centers for Disease Control and Prevention, 2012). As many as 84,000 cancer diagnoses each year are attributed to obesity, and obesity is implicated in $15 \%$ to $20 \%$ of total cancer-related mortality (National Cancer Institute, 2012; Calle, Rodriguez, Walker-Thurmond, \& Thun, 2003; American Cancer Society, 2012).

Defined as a condition characterized by the excessive accumulation and storage of fat in the body, obesity can be an unwelcome part of cancer survivorship. Obesity has been associated with an increased risk for recurrence of colorectal and breast cancers (in postmenopausal women; Marian, 2013). Obese men seem to be at increased risk of developing biologically aggressive prostate cancer (Efstathiou et al., 2007). A BMI of $\geq 35 \mathrm{~kg} / \mathrm{m}^{2}$ may be associated with an increased risk of colon cancer recurrence and mortality (Meyerhardt et al., 2003; Dignam et al., 2006) as well as other cancers. Oncology patients are often encouraged to prevent weight loss during treatments. However, when a patient completes active treatment and transitions into survivorship, weight loss may be needed.

After a cancer diagnosis and successful treatment, patients may be afraid and anxious about cancer recurrence. Obesity can place individuals at increased risk of developing second primary malignancies (Park, Choi, Jang, Jun, \& Kang, 2010; Li, Daling, Porter, Tang, \& Malone, 2009a; Li et al., 2009b), so patients are often told to achieve a healthy weight. Patients may be desperate for help with losing weight and often fall prey to "quickfix" schemes. Due to the anxiety of the cancer diagnosis and the trauma of cancer treatment, patients usually desire fast weight loss, with less regard to the safety of the weight-loss method. The methods patients find readily available often promise huge amounts of weight loss with little to no effort or exercise and may be costly, unhealthy, and even dangerous.

Many cancer survivors report attempts to make healthy changes after a cancer diagnosis (Demark-Wahnefried, Aziz, Rowland, \& Pinto, 2005). Careful planning is needed to help oncology survivors lose unwanted pounds. Ideally, a visit with a registered dietitian is part of survivorship care planning. This article will provide the AP with information about popular weight-loss methods and offer healthy weight-loss strategies to share with cancer survivors.

\section{POPULAR WEIGHT-LOSS METHODS}

The overall amount of weight a person needs to lose in a certain situation can often be a daunting number to absorb. The degree of weight loss required may cause patients to believe that the quicker the weight comes off, the better off they will be. Using a Google search, a person can find an overwhelming number of weight-loss methods and the most recent advice related to achieving weight loss effortlessly. Some of the popular trends in use today include the extreme $\mathrm{HCG}$ 
(human chorionic gonadotropin) diet and phentermine pills. During this search, one would also find some outlandish claims such as the Twinkie diet, the tapeworm diet, the cotton-ball diet, and ear stapling.

It is important for patients to remember that successful weight loss must have two key components: (1) It must be gradual, and (2) it requires work. If a diet or product sounds too good to be true, it usually is (Academy of Nutrition and Dietetics, 2016). Patients may not understand these components, so it falls to the registered dietitian or the AP (in the absence of a registered dietitian) to provide education.

\section{HCG Diet}

The HCG diet is one of the most popular current diet methods. According to an article in the May 2013 issue of the Annals of Pharmacotherapy, the HCG diet originally gained popularity in the 1950s (Goodbar, Foushee, Eagerton, Haynes, \& Johnson, 2013). Dr. Albert Simeons promoted HCG injections in combination with an ultralow-calorie diet of 500 calories per day. This article stated: "This weight loss strategy claims to redistribute body fat from the hips, thighs, and stomach, without undesirable effects such as hunger and irritability" (Goodbar et al., 2013).

Dangers: There are dangers associated with the use of higher amounts of HCG (Goodbar et al., 2013). In fact, Goodbar and colleagues reported an incident of deep vein thrombosis and bilateral pulmonary embolism associated with the initiation of the HCG diet. The HCG diet has "very few efficacy studies and no significant safety studies associated with its use" (Goodbar et al., 2013). Of the six studies identified for assessment of its efficacy, only one study was associated with significant weight reduction (Asher \& Harper, 1973). In addition, overall findings from a review of the available literature about the effects of HCG in the treatment of obesity "failed to demonstrate fat redistribution, reduction in hunger, or an improvement in well-being" (Toffle, 2011). Goodbar and colleagues (2013) noted that as the popularity of the HCG diet continues to increase, so do the potential adverse events associated with the management of weight loss via an unproven strategy.

\section{Phentermine}

There is a growing public mindset that a person can just "pop a pill" and successful weight loss will occur. Successful, permanent weight loss is more than just the use of pills for appetite suppression. One example of a weight loss pill is phentermine. Phentermine is "a noradrenergic drug that stimulates noradrenaline release and reduces food intake by acting on $\beta$-adrenergic receptors in the perifornical hypothalamus" (Bray, 1993).

Dangers: Phentermine exhibits actions similar to amphetamines. There are major safety concerns due to the cardioexcitatory effects of phentermine as monotherapy (Hainer \& Aldhoon-Hainerová, 2014). Although it was approved for short-term treatment of obesity by the US Food and Drug Administration (FDA) in 1959, long-term safety and efficacy evidence is still lacking (Li \& Cheung, 2009).

\section{FDA-Approved Weight Loss Drugs}

In 2012, the FDA approved two long-term weight loss drugs: (1) a combination of the drugs phentermine and topiramate (PT) and (2) lorcaserin. The combination of PT is indicated for use as an adjunct to a reduced calorie diet and increased physical activity for chronic weight management in adults with an initial BMI of $30 \mathrm{~kg} / \mathrm{m}^{2}$ or greater (obese) or $27 \mathrm{~kg} / \mathrm{m}^{2}$ or greater (overweight) in the presence of at least one weight-related comorbidity such as hypertension, type 2 diabetes mellitus, or dyslipidemia (Vivus, 2014).

Lorcaserin is a serotonin $2 \mathrm{C}$ receptor agonist indicated as an adjunct to a reduced calorie diet and increased physical activity for chronic weight management in adults with an initial BMI of 30 $\mathrm{kg} / \mathrm{m}^{2}$ or greater (obese) or $27 \mathrm{~kg} / \mathrm{m}^{2}$ or greater (overweight) in the presence of at least one weight-related comorbid condition such as hypertension, dyslipidemia, or type 2 diabetes (Arena Pharmaceuticals, 2012). The mechanism of action is stimulation of satiety centers found throughout the brain, which is thought to reduce hunger by the production of opiomelanocortin neurons in the hypothalamus (Mahgerefteh, Vigue, Freestone, Silver, \& Nguyen, 2013).

Dangers: Although data showed that PT did help patients lose weight over a 1-year time frame, there were also issues with harmful metabolic acidosis, memory, and attention or language prob- 
lems (Woloshin \& Schwartz, 2014). Common adverse effects reported with PT include paresthesia and dry mouth (Woloshin \& Schwartz, 2014). According to the prescribing information, the most common adverse reactions are paresthesia, dizziness, dysgeusia, insomnia, constipation, and dry mouth (Vivus, 2014).

Lorcaserin was approved by the FDA based largely on three major phase III trials (Mahgerefteh et al., 2013). However, weight was regained once use of the medication was discontinued, and patient outcomes were no better than in patients receiving placebo (Mahgerefteh et al., 2013). According to the package insert, the most common adverse reactions reported with lorcaserin in nondiabetic patients are headache, dizziness, fatigue, nausea, dry mouth, and constipation (Arena Pharmaceuticals, 2012). The most common adverse reactions in diabetic patients are hypoglycemia, headache, back pain, cough, and fatigue (Arena Pharmaceuticals, 2012).

\section{CRITERIA FOR APPROVAL OF WEIGHT=LOSS MEDICATIONS}

The FDA considers two criteria for approval of weight-loss medications: (1) whether participants lose $5 \%$ or more weight with the study drug vs. placebo, and (2) whether at least $35 \%$ of participants taking the drug lose at least $5 \%$ body weight (Woloshin \& Schwartz, 2014). For PT, both of these FDA criteria were met (Woloshin \& Schwartz, 2014). However, the combination medication was not the only intervention. Trial participants were also counseled to increase exercise and reduce caloric intake while taking any medications provided. Results over an additional follow-up of 1 year also showed that participants regained about $25 \%$ of the weight that they had lost (Woloshin \& Schwartz, 2014). Lorcaserin efficacy is also dependent upon decreasing caloric intake and increasing activity.

\section{Dietary Restrictions/Focus}

Sometimes patients resort to particular diet regimens that restrict part of or sometimes all of a specific food group in the quest for weight loss. Some examples include the cabbage soup diet, the grapefruit diet, and the no-carbohydrate diet. Adequate nutritional intake to meet nutritional needs should be balanced. Eating well is important to overall health, and when intake is not balanced or a particular item or group of food is eliminated, the nutritional result is unhealthy and inadequate. Balanced eating includes good protein sources (from plant or animal), fiber (including a variety of fruits and vegetables), carbohydrates, vitamins, minerals, healthful fats, and fluid (Academy of $\mathrm{Nu}$ trition and Dietetics, 2016).

\section{HEALTHY WEIGHT LOSS}

The American Society of Clinical Oncology has developed several priorities to address the obesity and cancer link. These priorities include education, awareness, clinical guidance, tools, resources, research promotion, and policy/advocacy (Ligibel et al., 2014). Evidence shows the most effective interventions for weight loss combine nutritional education, diet and exercise counseling, and behavioral strategies to help obese patients acquire the skills they need to successfully change their eating habits and to become more physically active (Wu, Gao, Chen, \& van Dam, 2009; Norris et al., 2004).

It is the position of the Academy of Nutrition and Dietetics that successful weight management to improve overall health requires a lifelong commitment to healthful lifestyle behaviors, emphasizing sustainable and enjoyable eating practices and daily physical activity (Seagle, Strain, Makris, Reeves, \& American Dietetic Association, 2009). Ultralow-calorie diets do not meet the recommended daily allowances for health.

Using inappropriate weight-loss methods may lead to less-than-desirable results. When a person ceases such inappropriate calorie restrictions, which cannot be sustained over a lifetime, weight will often increase. Patients are not taught how to eat in a healthy way or about the importance of exercise when they are just "popping a pill" for weight loss. There is a general misconception about getting healthy as a "diet" vs. a "lifestyle change."

In the absence of a registered dietitian, the tips found in the Table can be applied by the AP and used as a guide to help patients in their weightloss journey (Hager, 2014).

\section{SUMMARY}

The AP plays a vital role in helping cancer survivors achieve and maintain a healthy weight. The 


\section{Table. Tips for Successful Weight Loss}

\section{Portion Control}

- Eat at least 3 meals a day at consistent times.

- Try using smaller serving dishes and serving spoons for your meals.

- Do not place serving dishes on the table during meals. This will make a second portion more difficult to put on your plate. When you are finished eating your meal, take your plate away so you are not tempted to refill it.

\section{Trust Your Body}

- Pay attention to clues your body sends you. If you feel full during a meal, stop eating. If you are really hungry, you can choose additional healthy foods.

- If you think you are still hungry or feel unsatisfied after you eat, wait about 10 minutes. Cravings will often disappear if you give your body enough time to settle.

\section{Dining Out and Shopping}

- What about eating out? By all means, enjoy eating in a restaurant with family and friends.

- Consider asking your server to pack up half your meal in a to-go container before you even begin eating.

- Ask your server not to bring the bread basket.

- Share an entrée with someone or order an appetizer as an entrée.

- Be specific when ordering your meals. Specify items you would like served plain or without extra sauces or condiments. Order sauces on the side, so you can control how much you put on the food.

- When grocery shopping, always shop from a list. Preplanning your trips to the store takes time and effort, but it is worth it in the long run to help you stick to your goals and avoid problem foods in the store.

- Never go to the grocery store when you are hungry.

\section{Beverages}

- Hydration is very important. Make sure you maintain hydration but use calorie-free drinks (water, tea, or plain coffee). It is possible that you could be thirsty when you overeat, not hungry.

- To cut back on excess sugar, choose less fruit juice and less regular soda, as they add empty calories.

- Add a lemon or lime to sparkling water or seltzer for a refreshing, healthy beverage.

- Remember to limit alcohol intake (beer, wine, and liquor). Alcohol should be limited to 2 drinks per day for men and 1 drink per day for women.

\section{Lean Foods}

- Concentrate on lean meats, low-fat or nonfat cheeses, and skim or $1 \%$ milk. These products should be used in place of higher-fat/higher-calorie choices.

\section{Fiber}

- Fiber is important and needed for a healthy digestive system. Fruits, vegetables, and whole grains are good sources of fiber.

- Choose a high-fiber cereal for breakfast.

- Add fresh or frozen vegetables to a pasta dish to add fiber and nutrients.

\section{Eating at Home}

- Eat meals in one chosen location, preferably at the kitchen table. Do not eat in the car, in every room of your house, standing up, or in front of the TV.

- Create a calming atmosphere around your meals so you can really taste and enjoy your food.

\section{Snacks}

- Pick healthy snacks to eat and make sure to keep them on hand and readily available. Examples of healthy snacks include cottage cheese and fruit, apples and cheese, raw vegetables, raisins, and yogurt.

\section{Planning}

- Plan ahead for contingencies.

- Pack your lunch the night before.

- Plan your meals for at least a few days so you are not tempted to resort to fast food.

- When you go to a party, bring a healthy dish so you know you can eat something. Have a healthy snack before you go to a party so you do not overeat.

Note. Information from Hager (2014).

AP must maintain an accurate knowledge base of the current diet trends and their safety. When considering weight-loss medications or alternative methods as part of a patient's regimen, the AP must weigh both the risks and the benefits and effectively communicate them to the patient. Coun- seling, support, and referrals to a registered dietitian are all part of the oncology AP's role.

\section{Disclosure}

The author has no potential conflicts of interest to disclose. 


\section{References}

Academy of Nutrition and Dietetics. (2016). Staying away from fad diets. Retrieved from http://www.eatright.org/resource/health/weight-loss/fad-diets/staying-away-fromfad-diets

American Cancer Society. (2012). Cancer facts \& figures 2012. Retrieved from http://www.cancer.org/research/cancerfactsstatistics/cancerfactsfigures2012/

Arena Pharmaceuticals. (2012). Belviq (lorcaserin hydrochloride) tablets, for oral use. Retrieved from http://www.belviq.com/documents/Belviq_Prescribing_information.pdf

Asher, W. L., \& Harper, H. W. (1973). Effect of human chorionic gonadotrophin on weight loss, hunger, and feeling of well-being. American Journal of Clinical Nutrition, 26(2), 211-218.

Bray, G. A. (1993). Use and abuse of appetite-suppressant drugs in the treatment of obesity. Annals of Internal Medicine, 119(7 Pt 2), 707-713. http://dx.doi.org/10.7326/0003-4819119-7_Part_2-199310011-00016

Calle, E. E., Rodriguez, C., Walker-Thurmond, K, \& Thun, M. J. (2003). Overweight, obesity, and mortality from cancer in a prospectively studied cohort of U.S. adults. New England Journal of Medicine, 348(17), 1625-1638. http://dx.doi. org/10.1056/NEJMoa021423

Centers for Disease Control and Prevention. (2012). Defining adult overweight and obesity. Retrieved from http://www. cdc.gov/obesity/adult/defining.html

Cheung, B. M., Cheung, T. T., \& Samaranayake, N. R. (2013). Safety of antiobesity drugs. Therapeutic Advances in Drug Safety, 4(4), 171-181. http://dx.doi. org/10.1177/2042098613489721

Demark-Wahnefried, W., Aziz, N. M., Rowland, J. H., \& Pinto, B. M. (2005). Riding the crest of the teachable moment: Promoting long-term health after the diagnosis of cancer. Journal of Clinical Oncology, 23(24), 5814-5830. http:// dx.doi.org/10.1200/JCO.2005.01.230

Dignam, J. J., Polite, B. N., Yothers, G., Raich, P., Colangelo, L., O'Connell, M. J., \& Wolmark, N. (2006). Body mass index and outcomes in patients who receive adjuvant chemotherapy for colon cancer. Journal of the National Cancer Institute, 98(22), 1647-1654. http://dx.doi.org/10.1093/ jnci/djj 442

Efstathiou, J. A., Bae, K., Shipley, W. U., Hanks, G. E., Pilepich, M. V., Sandler, H. M, \& Smith, M. R. (2007). Obesity and mortality in men with locally advanced prostate cancer: Analysis of RTOG 85-31. Cancer, 110(12), 2691-2699. http://dx.doi.org/10.1002/cncr.23093

Goodbar, N. H., Foushee, J. A., Eagerton, D. H., Haynes, K. B., \& Johnson, A. A. (2013). Effect of the human chorionic gonadotropin diet on patient outcomes. Annals of Pharmacotherapy, 47(5), e23. http://dx.doi.org/10.1345/aph.1R755

Hager, K. K. (2014). Healthy weight loss for the cancer survivor. Journal of the Advanced Practitioner in Oncology, 5(4), 297-300. http://dx.doi.org/10.6004/jadpro.2014.5.4.8

Hainer, V., \& Aldhoon-Hainerová, I. (2014). Tolerability and safety of the new anti-obesity medications. Drug Safety, 37(9), 693-702. http://dx.doi.org/10.1007/s40264-0140206-3

Li, C. L., Daling, J. R., Porter, P. L., Tang, M. T., \& Malone, K. E. (2009a). Relationship between potentially modifiable lifestyle factors and risk of second primary contralateral breast cancer among women diagnosed with estrogen receptor-positive invasive breast cancer. Journal of Clini- cal Oncology, 27(32), 5312-5318. http://dx.doi.org/10.1200/ JCO.2009.23.1597

Li, D., Morris, J. S., Liu, J., Hassan, M. M., Day, R. S., Bondy, M. L., Abbruzzese, J. L. (2009b). Body mass index and risk, age of onset, and survival in patients with pancreatic cancer. The Journal of the American Medical Association, 301(24), 2553-2562. http://dx.doi.org/10.1001/jama.2009.886

Li, M., \& Cheung, B. M. (2009). Pharmacotherapy for obesity. British Journal of Clinical Pharmacology, 68(6), 804-810. http://dx.doi.org/10.1111/j.1365-2125.2009.03453.x

Ligibel, J. A., Alfano, C. M., Courneya, K. S., Demark-Wahnefried, W., Burger, R. A., Chlebowski, R. T.,...Hudis, C. A. (2014). American Society of Clinical Oncology position statement on obesity and cancer. Journal of Clinical Oncology, 32(31), 3568-3574. http://dx.doi.org/10.1200/ JCO.2014.58.4680

Mahgerefteh, B., Vigue, M., Freestone, Z., Silver, S., \& Nguyen, Q. (2013). New drug therapies for the treatment of overweight and obese patients. American Health \& Drug Benefits, 6(7), 423-430.

Marian, M. (2013). Energetics, exercise and cancer. In M. Leser, N. Ledesma, S. Bergerson, \& E. Trujillo (Eds.), Oncology nutrition for clinical practice (pp 41-46). Chicago, IL: Oncology Nutrition Dietetic Practice Group of the Academy of Nutrition and Dietetics.

Meyerhardt, J. A., Catalano, P. J., Haller, D. G., Mayer, R. J., Benson, A. B., 3rd, Macdonald, J. S., \& Fuchs, C. S. (2003). Influence of body mass index on outcomes and treatmentrelated toxicity in patients with colon carcinoma. Cancer, 98(3), 484-495. http://dx.doi.org/10.1002/cncr.11544

National Cancer Institute. (2012). Obesity and cancer risk. Retrieved from http://www.cancer.gov/cancertopics/factsheet/risk/obesity

Norris, S. L., Zhang, X., Avenell, A., Gregg, E., Bowman, B., Serdula, M.,...Lau, J. (2004). Long-term effectiveness of lifestyle and behavioral weight loss interventions in adults with type 2 diabetes: A meta-analysis. American Journal of Medicine, 117(10), 762-774. http://dx.doi.org/10.1016/j. amjmed.2004.05.024

Park, J. S., Choi, G. S., Jang, Y. S., Jun, S. H., \& Kang, H. (2010). Influence of obesity on the serum carcinoembryonic antigen value in patients with colorectal cancer. Cancer Epidemiology, Biomarkers \& Prevention, 19(10), 2461-2468. http://dx.doi.org/10.1158/1055-9965.EPI-10-0569

Seagle, H. M., Strain, G. W., Makris, A., Reeves, R. S., \& American Dietetic Association. (2009). Position of the American Dietetic Association: Weight management. Journal of the American Dietetic Association, 109(2), 330-346. http:// dx.doi.org/10.1016/j.jada.2008.11.041

Toffle, R. C. (2011). "There they go again"- hCG and weight loss. West Virginia Medical Journal, 107(1), 12-13.

Vivus. (2014). Qsymia (phentermine and topiramate extendedrelease) capsules, for oral use. Retrieved from http://www. vivus.com/docs/Qsymia_prescribing_information.pdf

Woloshin, S., \& Schwartz, L. M. (2014). The new weight-loss drugs, lorcaserin and phentermine-topiramate: Slim pickings? JAMA Internal Medicine, 174(4), 615-619. http:// dx.doi.org/10.1001/jamainternmed.2013.14629

Wu, T., Gao, X., Chen, M., \& van Dam, R. M. (2009). Long-term effectiveness of diet-plus-exercise interventions vs. dietonly interventions for weight loss: A meta-analysis. Obesity Review, 10(3), 313-323. http://dx.doi.org/10.1111/j.1467789X.2008.00547.x 